\title{
MIGRATION OF RETINAL PIGMENT IN THE EYES OF BRANCHIPUS GELIDUS
}

\author{
RUTH B. HOWLAND \\ FOUR FIGURES
}

\section{INTRODUCTION}

The general subject of pigment migration has received much attention during recent years. While it is not the purpose of this paper to deal with the movements of melanophore pigments, we can not disregard the effect which the study of this problem has had upon the study of the migration of retinal pigment. There can be no doubt that an intimate relation exists between the movements of the two forms of pigment, as there is no doubt concerning the morphological similarity existing between pigment spots and the eye spots of many of the lower animals.

The striking changes in coloration exhibited in chameleons early led to investigations as to the physical factors involved. Conclusive evidence showed that the movements of melanophore pigment was brought about largely by variations in light intensity and temperature. The work of Carlton ('03), Parker and Staratt ('04), and Parker ('06) is sufficiently well known to need only brief mention. Carlton found, in the case of Anolis, the outward migration of pigment in the pigment spots to be directly dependent on the action of the sympathetic nervous system, and the inward migration simply a return to the resting state.

In chameleons the migration was found to be under the control of the spinal nerves.

As these observations have been made only upon the marine crustacea, it was suggested to me by Professor C. W. Hargitt that a series of comparative studies upon a fresh water crustacean might be of some value. The occurrence of the Phyllopod, Branchipus, in a pond near Syracuse, and its especially promi-

THE JOURNAL OF EXPERIMENTAL ZOB̈LOGY, VOL. 11, NO. 2 
nent eyes made it a very favorable object for the investigation. In the spring of 1908 these crustacea could not be found at Syracuse, but material for experiments was obtained from Jordan, a small town seventeen miles west, and this supply was supplemented by material from Potsdam and the West, and fresh specimens from Syracuse in the spring of 1909 . Experiments were made and subsequent study conducted with a view to determining the effect of varied heat and light on the migration of retinal pigment in these eyes.

\section{HISTOLOGICAL METHODS}

The methods of preparation which gave the best results are, in brief, as follows:

1. For killing and fixing, hot picro-acetic acid was used. The animals were dipped in and held for a few seconds, then transferred to 80 per cent alcohol. Formalin proved unsatisfactory for fixation, and also rendered the material hard to stain in some cases. Corrosive sublimate fixation was also inferior to picroacetic.

2. a. Ehrlich's haematoxylin in toto or section gave the best results of any of the stains tried. If used for staining in toto, a a period of at least sixteen hours was necessary. When the sections were stained upon the slide, a minimum staining of ten minutes was allowed. The one stain was sufficient to show all features clearly, but eosin was occasionally used as a counter stain.

$b$. Iron-haematoxylin with counter stain of Bordeaux red also gave satisfactory results. The slides were treated as follows: left in iron-haematoxylin, a minimum of fifteen minutes; plunged into a $\mathrm{Fe}_{2} \mathrm{Cl}_{6}$ solution until sufficiently differentiated; washed in water; stained in aqueous solution of Bordeaux red for three minutes; dehydrated; cleared and mounted.

$c$. Borax carmine failed to give the desired differentiation.

d. Haidenhain's triple stain was temporarily satisfactory, but was not permanent.

3. Xylol proved to be the best clearing agent. Cedar oil was not so good. Material in toto required an hour at the mini- 
mum for clearing. Infiltration of at least one and one-half hours was necessary. Paraffin melting at $62^{\circ} \mathrm{C}$. permitted sectioning at from 3 to 5 microns.

4. To see clearly the nuclei of the retinular cells which in the normal eye are obscured by large masses of pigment, the following method of depigmentation was used:

Two or three drops of hydrochloric acid were poured over a few crystals of potassium chlorate. When the green color of the evolving chlorine appeared, a few cubic centimeters of 70 per cent alcohol were added. The eyes were allowed to stand in this bleaching fluid over night and subsequent staining revealed the retinular nuclei clearly.

\section{NORMAL STRUCTURE OF THE EYE}

Before entering upon a discussion of the experimental work, a brief description of the normal eye is essential.

The eye of this form is one of the simplest of compound crustacean eyes. It is stalked, and of such large size as to be a very prominent feature. The structural elements are fundamentally the same as those of other crustacean eyes, the unit being the ommatidium.

The histology of the eye of Branchipus vernalis is described in brief by Parker ('91) and others, and a more detailed account of the eye of Branchipus stagnalis is given by Nowikoff ('05).

The outer surface of the eye is covered with a structureless cuticula, presumably a secretion of the underlying hypodermal cells. In Branchipus vernalis it is obviously facetted, having the form of concavo-convex elevations.

According to Patten, the hypodermal cells in B. grubei are of indefinite arrangement, but Claus and Nowikoff find in B. stagnalis a regular arrangement which the latter shows diagrammatically in the following way: the hypodermis covers the distal end of each ommatidium as a cuticular cap made up of six equal cells extending radially from the center to the circumference of the circle. The nuclei are oblate, and lie upon one side. The intervening space is filled by two cells with round nuclei. These nuclei are extremely large and extend at an acute angle into that 
part of the cell lying between the cone cells. This arrangement as well as the facetted condition of the cuticula (both disputed points) have been observed in my preparations of the species found here.

The cone cells are four in number, of equal size and regular form. The crystalline cones are ellipsoidal and their mass in comparison with that of the cone cells is large. The nuclei of the cone cells were not found by Claus in the adult, and only indistinctly seen in the larvae. Nowikoff, however, states that they are well defined in his preparations, lie close under the crystalline cones at the promixal ends and are sphere shaped, while Patten finds these nuclei lying over the distal end of the cells like a cap.

In regard to the exact location of these nuclei, it seems to me that there has been a great deal of confusion arising from incomplete knowledge of the histology of the hypodermal cells. Patten, as I have previously stated, regarded the hypodermis as consisting of a "layer of indefinitely arranged cells" and the four cone cell nuclei as forming a cap over the crystalline cones. These nuclei, described as forming a cap over the crystalline cones, might be those of the hypodermal cells in their characteristic radial arrangement as shown by Nowikoff. If this were the case, Patten's description would agree with B. stagnalis as to the location, but not as to the number of the hypodermal nuclei. Nowikoff, however, goes a step further in identifying the cone cell nuclei.

I regret to have to say that in my own preparations I have been unable to confirm Nowikoff's or Patten's statement as to the location of these nuclei, though I have directed special attention to this point. It is a most peculiar circumstance that cells of this size and importance should fail to show clearly a definite nuclear structure.

A peculiar condition in one series may be worth considering in connection with this point. This series, cut at 5 microns, shows, under the one-sixth inch objective, structures which even upon critical examination appear as nuclei of the cone cells at the level of the distal ends of the retinular cells. A slight enlarge- 
ment of the rhabdom at this place furthers the impression that we are looking at nuclear structures. Similar structures, though less evident, can be seen scattered elsewhere at various levels. They are of comparatively large size and appear round and very similar to the nuclei pictured by Nowikoff in B. stagnalis. Nuclear structures, if present in this level, would easily escape even careful observation; for unless the section be extraordinarily thin and exactly in the plane parallel to the rhabdom, the ends of the pigmented retinular cells would obscure them.

However, a closer study under a one-twelfth inch oil immersion lens shows these structures rather as reticulated fibrils of the cytoplasm of the cone cells with scattered pigment granules forming pseudo-nucleoli. Had these structures been constant in all of my slides, I would have been assured of the fact that they were nuclei, but their scarcity, the reticulated structure of the cytoplasm of these cells, and their appearance under the oil immersion lens forces the conclusion that they are artifacts.

The rhabdom is slender and in continuation with the cone cells (Nowikoff); it extends approximately three-fourths of the entire length of the ommatidium terminated proximally by the basement membrane, and is surrounded its entire length by the five retinular cells. The retinular cells contain a large quantity of pigment granules. Their cytoplasm is fibrillar, extending below the basement membrane as fibrils. The nuclei are oval and lie in the larger distal ends of the cells.

The nucleated basement membrane separates the retinal and nerve-fiber regions. It is perforated where the retinal cells penetrate it (Nowikoff, '05).

Blood corpuscles are found in varying numbers between the ommatidia, and especially upon the ventral side of the eyes. This was particularly noticeable in a large number of preparations, and is doubtless due to the close proximity of a large ventral sinus.

A comparison of sections of the eyes of $B$. vernalis and $B$. gelidus with the plates and descriptions of $\mathrm{B}$. stagnalis given by Nowikoff show no differences of structure. The nuclei of the cone cells I was, of course, unable to compare. 
An article by Dietrich ('09) came to my notice after the completion of the above discussion. It comprises an extensive description of the facetted eyes of diptera, and contains points of general interest in their bearing upon the problem under discussion. Mention is made of the fact that deep-sea crustacea have a greater number of elements in each ommatidium-possessing as a rule seven - than do the crustacea of a more pelagic habit, whose ommatidial elements have been reduced to five. An explanation of this is offered by the fact that the difference in intensity of light which these two extremes receive has possibly led to the reduction as an adaptive feature.

Another feature which calls forth comparison with the structure of the phyllopod eye is the location of the nuclei of the cone cells. In some species of diptera, these are found directly beneath the pseudocones, while in others they lie further proximally. Their appearance in the latter case closely resembles the structures in my preparations already described, which closer study revealed as artifacts.

\section{EXPERIMENTS}

An account of the experiments tried may perhaps best be given in tabulated form:

\begin{tabular}{|c|c|c|c|c|}
\hline SPECAES & HOW KILLED & LIGFT OR DARK & TIME & TEMP. \\
\hline & & & & Deg. C. \\
\hline B. gelidus........ & Corrosive sublimate & Dark & 9 hrs. & 5.5 \\
\hline B. gelidus........ & Corrosive sublimate & Dark & $8 \mathrm{hrs}$. & 20.0 \\
\hline B. gelidus... & Hot picro-acetic & Dark & $4 \frac{1}{2}$ hrs. & 24.0 \\
\hline B. gelidus... & Corrosive sublimate & Diffuse light & $8 \mathrm{hrs.}$ & 17.0 \\
\hline B. gelidus..... & Corrosive sublimate & Diffuse light & 9 hrs. & 55.0 \\
\hline B. gelidus..... & Hot picro-acetic & Sunlight & $\begin{array}{l}\text { Killed at } \\
\text { six o'cloek }\end{array}$ & 19.0 \\
\hline B. gelidus. . & Hot picro-acetic & Sunlight & $1 \frac{3}{4} \mathrm{hrs}$ & 21.0 \\
\hline B. gelidus..... & Hot picro-acetic & Dark & $16 \mathrm{hrs}$. & 21.0 \\
\hline B. vernalis..... & Hot formalin & Dark & 5 hrs. & $?$ \\
\hline B. vernalis.... & Picro-acetic & Dark & 5 hrs. & $?$ \\
\hline B. gelidus... . & Hot picro-acetic & Dark & $30 \mathrm{~min}$ & 19.0 \\
\hline B. gelidus. . & Hot picro-acetic & Dark & $15-20 \mathrm{~min}$ & 19.0 \\
\hline B. gelidus. & Hot ipero-acetic & Dark & 2 hrs. & 5.0 \\
\hline B. gelidus. . & Hot piero-acetic & Dark & 2 hrs. & 21.0 \\
\hline
\end{tabular}


The animals were taken from the pond and experiments made upon them without delay, for the character of all reactions was noticeably modified by keeping them for twenty-four hours in an aquarium. A loss of vitality, fading out of color, etc., became evident within a day unless the aquarium was kept at very low temperature, with a supply of soft mud in the bottom.

In all the experiments, the largest, most active specimens of both sexes were chosen. The experiments in light and dark were conducted as follows:

a. A few animals were placed in the direct sunlight, after allowing them to stand in a warm room until the water had been gradually raised to room temperature. In the early part of the season this method was found to be impossible. The maximum temperature at which they will live changes with the advanicing season, and while early in the season the room temperature of $21^{\circ} \mathrm{C}$. will kill them almost immediately, later the maximum is raised to from $26^{\circ} \mathrm{C}$. to $29^{\circ} \mathrm{C}$. The range of temperature between the optimum and the maximum for these animals, however, does not seem to vary. With a higher optimum, a higher maximum temperature ensues, but the range between these two appears to have a certain constancy of $5-8^{\circ} \mathrm{C}$.

$b$. On a cloudy day, an aquarium with a few specimens was set out of doors and allowed to stand for nine hours. The average temperature for that time was $5.5^{\circ} \mathrm{C}$. and the few degrees of variation above or below were not considered of sufficient value to appreciably modify the result. The same experiment was twice repeated with aquaria upon a table in the center of the room, out of the direct rays of the sun, at temperatures of $17^{\circ} \mathrm{C}$. and $20^{\circ} \mathrm{C}$. for periods of eight hours.

$c$. In conducting the experiments in the dark, the greatest care was taken to exclude every means of access of light rays. The animals were placed in a tall glass dish, which was wrapped in light-proof paper. This was then either placed in a tin box and covered tightly, or left in the photographic dark room for the required length of time. The paper was then removed, and a flash of light thrown into the jar to assure the fact that all were 
alive. The water was at once drained off and the specimens thrown into the killing fluid, heated to $60^{\circ} \mathrm{C}$.

In preparing the eyes for sectioning it was found that the liability to injury from handling was greatly reduced by dehydrating and clearing the entire animal before separating the eyes from the body. After infiltration was complete, the eyes were removed from the body and imbedded with special attention as to orientation for transverse or longitudinal sections as desired.

\section{CONDITIONS FOUND}

A discussion of the conditions found in the material sectioned falls naturally under three heads: first, the effect of light; second, the effect of heat variation; and third, the relation of pigment migration to phototropism.

1. In these examinations care was taken to compare those sections cut at equal thickness, and to select those parts of the sections (long) where the plane of cutting was parallel to the long axis of the rhabdom.

$a$. In eyes which have been killed after exposure to the sun for a period of one and three-fourths hours the pigment is in the following condition: In the distal parts of the retinular cells the granules are accumulated in great quantities, so that it is impossible to distinguish the nuclei of these cells, which are located here. The entire length of the rhabdom is closely protected with a heavy layer of pigment, and here the lateral portions of the cells are much clearer as compared with the distal part. In the proximal third of the cells there are proportionately smaller quantities. Pigment is also heavily deposited below the basement membrane, and for a short distance along the nerve fibers. In eyes exposed to sun for longer periods, the conditions are identical. (Figs. 1 and 3.)

b. In diffuse light for eight hours, the pigment granules are still heavily deposited in the distal ends of the cells, and along the rhabdom. The lateral portions of the retinular cells, as in the case of sunlight, are much clearer than the densely pigmented region close to the rhabdom. The direct sunlight thus seems to produce no appreciably greater response of pigment than the diffuse light of a partly cloudy day. 


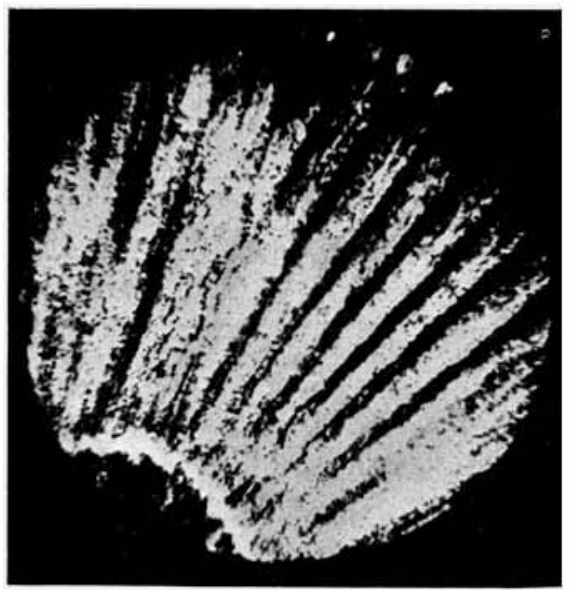

1

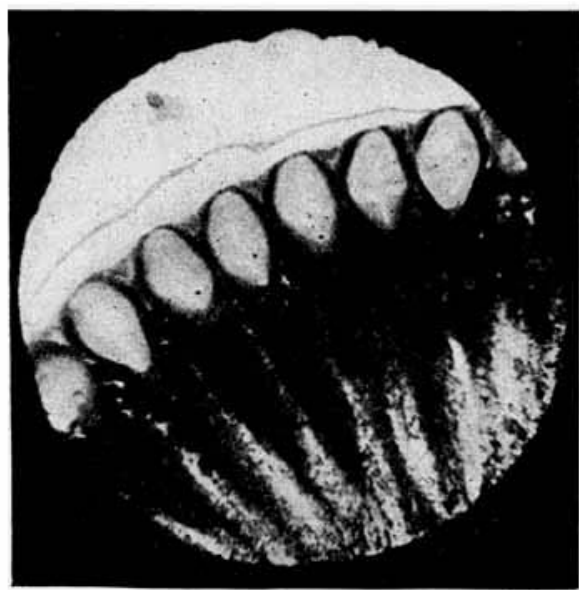

2

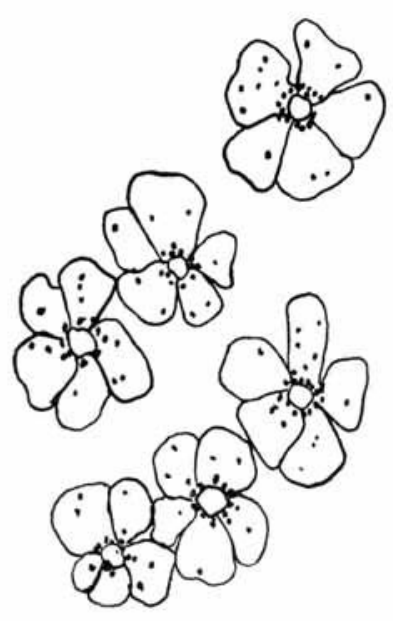

3

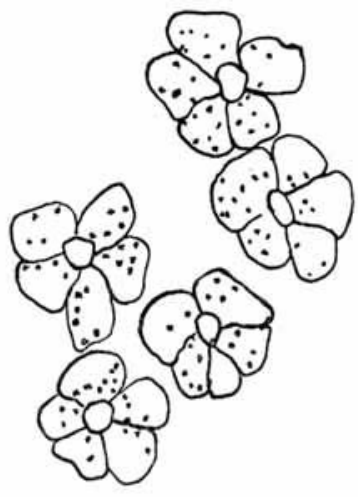

4

Fig. 1 Pigment conditions after exposure to sun until 6 p.m. on a sunny day. Rhabdoms covered with pigment.

Fig. 2 Pigment conditions after remaining in dark four and one-half hours. Readjustment of pigment through a lateral migration leaves rhabdoms exposed.

Fig. 3 Transverse section of ommatidia after exposure to sun for five hours. Conditions as in fig. 1. (Oil immersion, camera lucida.)

Fig. 4 Transverse section of ommatidia after remaining in dark four and onehalf hours. Conditions as in fig. 2. (One-twelfth oil immersion, eamera lucida.) 
c. Eyes sectioned after remaining in the dark fifteen minutes, twenty minutes, and a half hour, show no appreciable movement or migration of pigment granules. The conditions do not vary from those in diffuse light to any appreciable degree. Pigment is heavily deposited for a short distance down the nerve fibers below the basement membrane.

$d$. In the eyes which have been in the dark for two hours, the pigment has begun its lateral migration and forms an intermediate stage between the two extremes $a$ and $e$.

$e$. The eyes which have been in the dark four and a half hours, show the pigment closely packed in the distal ends. The granules are not packed close to the rhabdom as in sun and diffuse light, but are scattered laterally in the cytoplasm by a lateral migration or a readjustment. The outline of the rhabdoms is thus not so clearly defined by a heavy boundary of pigment granules, but their surfaces are more exposed. The entrance of light rays would result in a more intense stimulus than under the previously described conditions. A dense accumulation of pigment occurs below the basement membrane and proximally down the nerve fibers (fig. 2 and fig. 4).

$f$. In eyes left in the dark from eight to sixteen hours, these variations in pigment location become less and less evident, and in general the eye assumes the appearance of those killed in direct sunlight. The distal pigment is closely packed around the rhabdom and the retinular nuclei, the pigment in the proximal part lying close to the rhabdom. Eyes which have been in the dark for eight hours or more were thus not considered in drawing conclusions as to the effect of light and dark.

The adaptive movement of pigment granules in these eyes would thus appear rather as a rearrangement or readjustment of the pigment granules in the retinular cells than as a pronounced migration proximally in the dark, and distally in the light. A proximal migration in the dark would result necessarily in an accumulation of pigment below the basement membrane, which would increase gradually from the light conditions to the completion of the migration. The pigment masses beneath the membrane would thus vary in a graded series, a condition which 
does not occur in my preparations. The pigment deposited beneath the membrane is quite as dense in sunlight as in dark. The distal pigment in all my preparations is densely packed around the rhabdom and the retinular nuclei, and shows no sign of movement due to light or temperature changes.

The protective function of the pigment is accomplished in a different way. A lateral movement of the granules exposes the rhabdom in the dark, while an opposite movement in the light brings them close against the rhabdom. Since these eyes have no accessory pigment cells, which in other crustacean eyes serve as a reflecting apparatus in the dark, the cytoplasm of the retinular cells must perform this function.

So, unlike the eyes of Cambarus and Gammarus, the proximal and distal migrations of pigment granules are not found in $\mathrm{B}$. gelidus, but are replaced by a lateral migration, outward in the dark, centrally toward the rhabdom in the light, while the protective function of the pigment remains the same.

2. The temperature changes, so far as I have been able to note, produced no appreciable effect on the migration of the pigment. High temperatures were of course impracticable in experimental work, causing almost immediate death. In eyes exposed to diffuse light at $5.5^{\circ} \mathrm{C}$. and $17^{\circ} \mathrm{C}$. no difference could be noted in the distribution of the pigment.

3. Experiments were made with a view to determine the degree of phototactic response, and also its possible bearing on the movement of the pigment.

a. A dozen animals, which had just been brought in from the pond, were put into an aquarium in a large amount of pond water at $21^{\circ} \mathrm{C}$. Of this number, five were young specimens, the others adults. Light from a 16-candle power lamp was thrown into the aquarium from above with the following results:

11 were strongly positive. 1 female was indifferent.

The two youngest specimens made frantic efforts to approach nearer the light beating their heads against the sides of the aquarium. The light was then placed below the jar. Nine responded at once by following the light. One male, one female, and one young specimen were indifferent for a period of three minutes, 
when they too went to the bottom. If the light were held below the jar, the tendency to orient themselves with their long axes perpendicular to the source of light was stronger than the habit of swimming with the appendages upward, and they stood upon their heads making futile efforts to reach the light.

$b$. A larger number of animals was then put into the jar and the same experiments repeated. The younger ones showed a much quicker and more positive response than the adults. The depth of the water effected no change in the character of the response. Special attention was given to the occurrence of the animals in their natural habitat, to determine whether the responses given in the laboratory were merely artificial or whether, even in the natural environment, the direction of the light rays had a noticeable effect on the location of these crustacea. On a bright, sunny afternoon, when the water was $11^{\circ} \mathrm{C}$. a much larger number of specimens was found swimming on the west side of the pond than on the east side. They were not, however, very active, on account of the low temperature, but for the most part were swimming slowly along the bottom about an inch above the mud. For some time, the direction of the wind was thought to have a marked influence on the distribution in the pond, but the wind on this day was blowing from the northwest, and the animals must have gone almost directly against the wind in order to appear in such large numbers on the western side of the pond.

$c$. The temperature of the water in one jar was gradually raised by the addition of small amounts of hot water. Pond water was heated for this purpose to guard against the addition of any chemical which might influence the response. When the water reached $24.9^{\circ} \mathrm{C}$. to $25.5^{\circ} \mathrm{C}$., the light was placed above the jar. The animals responded positively as in $b$. They became very active, and the branchipeds greatly increased their rate of motion. As the temperature reached $27^{\circ} \mathrm{C}$, convulsive jerkings became frequent, jerking the animals almost out of the water when they came to the top in response to light. Between $27^{\circ} \mathrm{C}$. and $29^{\circ}$ C. they became less and less active and sank to the bottom of the jar. At $31^{\circ} \mathrm{C}$. they were all dead. The increase in temperature does not, therefore, cause a negative response, but merely 
a greater activity which finally leads to spasmodic muscular contraction and death.

Numerous reports of photomechanical changes in retinal pigment have appeared referring to amphibia, cephalopoda, and arthropoda. Exner ('91) and Parker ('97 and '99) record the effect of changes in light intensity on retinal pigment in Palaemon and Gammarus.

These reports have led without exception to the conclusion that the same laws of migration which hold true in the case of melanophore pigment apply as well to the migration of retinal pigment under various degrees of illumination. The uniformity of the effect of heat, however, has only recently been acknowledged. Kühne ('79) observed that the retinal pigment in frogs' eyes in darkness was withdrawn further proximally in a high than in a low temperature. Herzog ('05) confirmed and amplified these results, and further stated that while increased heat produced a proximal migration, decreased temperature a distal migration between $0^{\circ}$ and $18^{\circ} \mathrm{C}$., above this temperature exactly the reverse took place. The question of temperature influence was resumed several years later by Congdon ('07) in the case of Arthropod eyes. Experiments on Palaemonetes and Cambarus confirmed the previously published results of Kühne and Herzog. Response to raised or lowered temperature in these crustacea is much weaker than photomechanical response, and probably of no functional importance, as the migration due to temperature change occurred much above normal conditions.

As to the physiological importance of retinal migrations due to varied light conditions, there is no doubt that the distribution of the pigment along the sensitive parts of the eye protects it from too intense illumination by the absorption of light rays; while on the other hand, the withdrawal of pigment from them gives easy access to the non-injurious rays of diffuse light. In eyes which possess, in addition to the dark pigment cells, whitish accessory pigment cells (Palaemon, according to Congdon, '07) these cells serve to reflect light rays into the rhabdom on withdrawal of the pigment in diminished light. 
In addition to this protective result the migration of retinal pigment has a bearing upon the phototropic response of animals in which this occurs. Gammarus annulatus shows (Smith, '05) pronounced migration of pigment, and accompanying this a marked change in behavior toward the light stimuli. The close correlation of these two facts in matter of time, points towards the fact that the change from negative phototropism to a marked positive response is due to the exposure or protection of the rhabdom by movement of the pigment.

d. The effect of a moving light was then tried. A light was held above the jar until the usual response was given, and the number of negative or indifferent specimens counted. Then it was moved slowly around the jar. In every case the positive response was greater, and more definite with the moving than with the stationary light.

e. A larger number of animals was placed in an aquarium and allowed to stand in the dark for an hour at room temperature. They were then exposed to light. They remained indifferent for a short period before any definite response was noted, but then gave a positive response.

Another aquarium was tightly wrapped in black paper and made thoroughly light-proof. This was placed out of doors (about $19^{\circ} \mathrm{C}$. and allowed to remain for five hours. It was then taken to a photographic dark room and opened under a light of 16-candle power intensity. The majority of the specimens were negative for a period of from two to three minutes, but after remaining in the light, gradually became positive as under the usual conditions.

The same specimens were at once placed in the dark and left for two hours longer. When exposed to the light, the negative reaction was even more definite than before. ${ }^{1}$

\footnotetext{
'In a recent paper on phototropic responses of Branchipus (McGinnis, '11) the statement is made that Branchipus is never negative to light, even after exposure to darkness, but no record is made of the time necessary to bring about the normal response after this exposure. The peculiar "reversal of geotropic response" recorded in the same paper $(p, 237)$ may have been influenced by negative response to light, the other positive responses to gravity being, as suggested, simply the natural falling of bodies.
} 
The reversal of the response in my experiments is obviously related to the movement of the pigment in the eyes. As the previous results have shown the condition of the eye at the end of five hours to be one in which the sensitive rods are exposed to the fullest extent, the sudden entrance of a strong light would naturally cause a negative reaction. The fact that in the first experiment an exposure to 16 -candle power light did not cause this negative response is doubtless due to the incomplete migration of the pigment in the shorter period of time.

\section{SUMMARY OF RESULTS}

1. The effect of light and dark on the movement of pigment granules in the eye of Branchipus gelidus is in the nature of a readjustment rather than a proximal and distal migration.

2. The distal pigment is not influenced by variation in light intensity.

3. In light, the pigment granules collect elosely around the rhabdoms, protecting them from too intense stimulation.

4. In the dark, the granules move laterally and are readjusted so that they become more evenly distributed through the cytoplasm of the retinular cells.

5. The time occupied in complete readjustment is between four and one-half and five hours.

6. The cytoplasm of the retinular cells serves as a reflecting apparatus in a weak light in the absence of accessory cells.

7. Changing temperatures have no appreciable effect upon pigment migrations, higher temperatures causing almost instant death.

8. Branchipus gelidus is positively phototropic. Animals exposed to light after remaining in the dark five hours were negatively phototropic. 


\section{BIBLIOGRAPHY}

Carlton, F. C. 1903 The color changes in the skin of the so-called Florida chameleon, Anolis Carolinensis Cuv. Proc. Amer. Acad. Arts and Sci., vol. 39, no. 10, pp. 237-276, 1 pl.

Dahlgren and Kapner 1908 Principles of animal histology.

Dretrich, Wratelm 1909 Die Facettenaugen der Dipteren. Zeit. für wiss. Zoöl., Bd. 92, Heft 3.

HAT, O.P. AND W. P. 1889 A contribution to the knowledge of the genus Branchipus. Am. Nat. February, vol.23, no. 266, pp. 91-95.

Herzog, H. 1905 Experimentelle untersuchungen zur Physiologie der Bewegungvorgänge in der Netzhaut. Arch. f. Anat. u. Physiol., Physiol. Abt. Jahrg. Heft 5-6, pp. 413-464, Taf. 5. (Original not available.)

KüHNE, W. 1879 Chemis he Vorgänge in der Netzhaut. M. L. Hermann, Handbuch der Physiol., Bd. 3, Theil 7, pp. 235-342. (Original not available.)

McGinnis, Mary O. 1911 Reactions of Branchipus serratus to light, heat and gravity. Jour. Exper. Zoöl., vol. 10, no. 2, pp. 227-239.

Nowikoff, M. 1905 Uber die Augen und die Frontalorgane der Branchiopoden. Zeit. für wiss. Zoöl., Bd. 79, Heft. 3, pp. 432-464, Taf. 2.

Packard, A.S. 1878 A monograph of the phyllopod crustacea of North America, with remarks on the order phylloearida. U. S. Geol. and Geog. Survey of the territories of Wyoming and Idaho, 1879, pp. 295-514. Part 1, $39 \mathrm{pl}$.

PArker, G. H. 1891 Compound eyes in crustacea. Bull. Mus. Comp. Zoöl, Harvard Coll., vol. 21, no. 2, pp. 45-140, $10 \mathrm{pl}$.

1897 Photomechanical changes in the retinal pigment cells of Palaemonetes, and their relation to the central nervous system. Bull. Mus. Comp. Zoöl., Harvard Coll., vol. 30, no. 6, pp. 273-300, 1 pl.

1899 The Photomechanical changes in the retinal pigment of Gammarus. Bull. Mus. Comp. Zoöl., Harvard Coll., vol. 35, no. 6, pp. 141$148,1 \mathrm{pl}$.

1906 The influence of light and heat on the movement of the melanophore pigment, especially in lizards. Jour. Exper. Zoöl. Vol. 3, no. 3 , pp. 401-414.

Parker, G. H. ANd Staratr, S. A. 1904 The effect of heat on the color changes in the skin of Anolis Carolinensis Cuv. Proc. Amer. Acad. Arts and Sci., vol. 40, no. 10, pp. 455-466.

Rogers, C. G. 1906 A chameleon-like change in Diemyctylus. Biol. Bull., vol. 10, no. 4, March.

Surrh, Grant 1905 Effects of pigment migrations on phototropism of Gammarus annulatus. Am. Jour. Physiol, vol. 13. 